\title{
Image Color Extraction of Forest
}

\author{
Dyah Pratiwi \\ Gunadarma University \\ Margonda Street No. 100 \\ Depok, Indonesia
}

\author{
Lussiana E.T.P \\ STMIK JAKARTA STI\&K \\ BRI RADIO DALAM Street No. \\ 17 \\ Jakarta, Indonesia
}

\author{
Sarifuddin Madenda \\ STMIK JAKARTA STI\&K \\ BRI RADIO DALAM Street No. \\ 17 \\ Jakarta, Indonesia
}

\begin{abstract}
Indonesia has vast tropical forests and rich biodiversity. The occurrence of change rate in forest area generally is caused by extreme weather changes, destruction of the ozone layer, floods and landslides that can damage system imbalance of environment. The destruction of forests (deforestation) in Indonesia in the period from 2003 to 2006 reached 1.17 million hectares per year. This research needs to perform the interpretation of satellite imagery for monitoring and calculating of change rate in forest area, in order to identify forest area and separation from other areas and need to know the calculating of forest area and monitoring of its changes at any time in accordance with forest shooting by satellite. The purpose of this study is to develop an image analysis system is used for monitoring and calculating of change rate in forest area which is obtained from satellite imagery. The focus of this study, is to determine type of color space which is the most suitable for used and can represent exact color of the forest in a satellite image.
\end{abstract}

\section{General Terms}

Image Processing.

\section{Keywords}

Segmentation, satellite image, color, change rate, forest.

\section{INTRODUCTION}

Population growth in an area can influence either directly or indirectly to the existence of the forest, such as the shifting cultivation and uncontrolled logging. It is so potentially damaging to the existence and preservation of forests, which in turn can have an impact on the environment system imbalances. Some examples of imbalance are: extreme weather change, the destruction of the ozone layer, floods, and landslides. Other effects that can arise is the extinction of various species of flora and fauna. Thus, prevention of forest destruction is necessary to maintain the viability of a balanced diet and a good living environment.

While there are several ways to monitor forest conditions, particularly the condition of forest destruction, namely through the aircraft, as well as with remote sensing technologies, such as satellites. The results in the form of image data acquisition forests containing extensive information forests of a region at the time or period. Meanwhile, image processing applications have been used almost in all fields, such as education and research, medical, military, police and geophysics. In connection with the acquisition of the satellite image of forest yield, image processing applications has also been applied among others, to identify the presence of rivers, land, and trees.

Several previous studies associated with the image of the forest is the application of texture and color segmentation in forest area by [1]. The study was a combination JSEG method for area-based segmentation of color and texture features based on wavelet transform. In general, this method is successfully applied to get an edge delineation of the forest, but the difference image in the lighting conditions, making this method needs to be optimized further. [2] conducted a study by reviewing some of the color space transformation Radiometric existing canal and texture features as well as investigating the combination of inputs that gives the best results for the segmentation of multispectral aerial photography, the segmentation algorithm hierarchical. The combination of color and texture segmentation give good results, however the changes and differences in color channels affect the results obtained. [3] discusses an algorithm that combines color and texture to the color image are applied to aerial images. The algorithm used is the maximum likehood classification criteria combined with fusion. Deficiencies that exist in this research is the need to reduce noise (noise) and further classification related to the density function.

Currently, the forest area calculation is done manually, by forming polygons directly on the image, then calculate the area of each polygon formed. It requires persistence and thoroughness of experts to form polygons. Moreover it is potentially there is a difference between a forest tally with other learned scholars, causing widespread confusion forest information.

On the other hand the results of satellite image acquisition of the existence of the forest can be optimized by using image processing technology for forest monitoring, particularly in terms of forest area changes either because of deforestation or forest growth itself. Under these conditions, the focus of this study is to find an alternative solution by utilizing image processing technology to determine changes in forest area automatically, quickly and accurately. This study use the color transformation as a first stage.

\section{THEORETICAL CONSIDERATION 2.1 Basic Concept Image Processing}

According to [4], the image is a representation of an object. The image can be expressed as a form or object in the form of visual images. The image is a collection of dots arranged in two-dimensional space which is expressed in a matrix of size $\mathrm{N}$ rows and $\mathrm{M}$ columns. Each point is called the smallest element of an image or picture element or simply mop / pixel. Each pixel is a part of forming the visual information contained in each image, as illustrated in figure 1. 


$$
F=[f(i, j)]=\left[\begin{array}{cccc}
f(0,0) & f(0,1) & \ldots & f(0, M) \\
f(1,0) & f(1,1) & \ldots & f(1, M) \\
\vdots & \vdots & \ddots & \vdots \\
f(N-1,0) & f(N-1,1) & \ldots & f(N-1, M-1)
\end{array}\right]
$$

\section{Figure 1: Equation of Image Ilustration}

Value of each element of $f(i, j)$ in the matrix $F$ represents the intensity of the color of a digital image. Each value is expressed in binary code form, for example in 24 bits per pixel (24 bpp) for color or image in 8 bits per pixel ( $8 \mathrm{bpp}$ ) for gray level image. [5]. When viewed from the perspective of the image can be represented mathematically as a continuous function of twodimensional (2D) of the light intensity $f(x, y)$, where $x$ and $y$ are spatial coordinates of the image elements (pixels). The image can be divided into two types namely analog image or continuous, and discrete or digital image. Analog image is generated image of the optical system in the form of analog signals, such as those produced by an analog camera or image display on the monitor screen (video signal). Digital images obtained through the digitization of analog images, which transform continuous image into a digital image. To change the image into a digital image required continuous sampling and quantization process, in order to obtain images in the form of two-dimensional arrays. Some equipment that can produce digital images such as digital cameras, scanners and camcorders. Image contains a lot of information, but in reality it is often because of a thing, the image obtained decreased quality, such as an interference or noise, the color is too light or contrast, less sharp, blur and so on. As a result, the image of the condition thus becomes difficult to interpret. On the other hand, the need to obtain accurate information is very important. Thus the necessary process of image manipulation or image processing increasingly necessary, so as to help interpret the information content in an image. Image processing or image manipulation process becomes easier and more effectively done if you use a computer, so the image is processed must be represented numerically with discrete values [6]. Figure 2 shows an example of a digital color

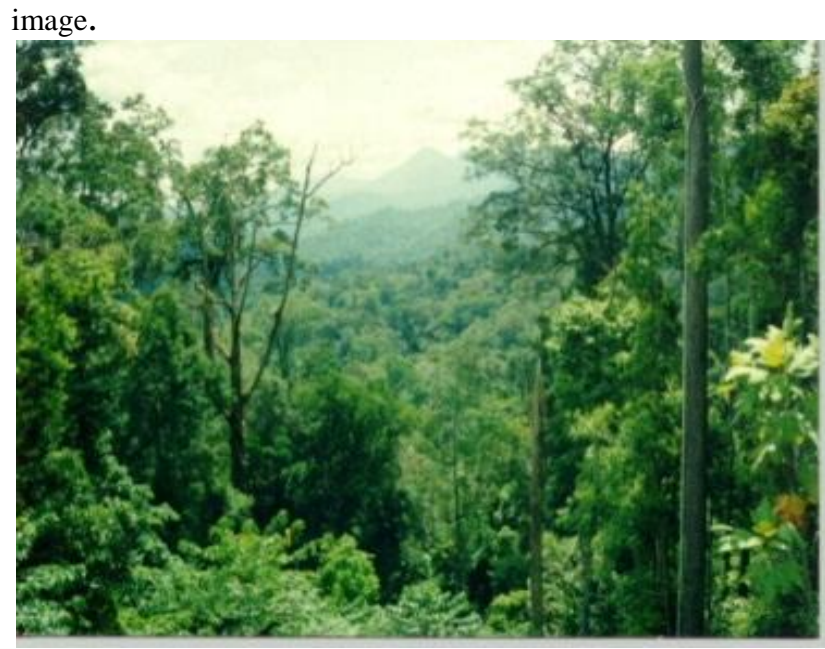

Figure 2: Digital Color Image (Source: www.irwantoshut.net/pict-rain-forest.jpg) [7]

\subsection{Image Characteristics}

Associated with the image, the visual characteristics of a feature or content of an image that provides important information such as color, shape and texture of objects. In this paper discuss the first characteristic that is color characteristics. In the human visual system, the eye is very sensitive to a variety of colors contained in an object or image. According to [8], the human visual system is able to distinguish between hundreds of thousands of shades of color, but to model the gray image, it can only distinguish 100 shades of gray levels. Therefore, the use of color images in image processing is important because it can help facilitate the process of image analysis. Image color is called true color because the image has a sizable number of colors and cover almost all natural colors. This image is composed of three primary colors are red (R), green $(\mathrm{G})$ and blue (B). Unlike the gray image, one pixel in the color image has three kompnen colors R, G and B, each of which is encoded with 8 bits or 24 bits total (three bytes). Thus, a color image can have as many variations of color content of 224 (16777216 colors). Figure 2 is an example of color image representation. The results of the analysis based on color image depends on the color space as well as the algorithm used. Several color spaces have been developed by a number of researchers such as RGB, L $* \mathrm{C} * \mathrm{H}$, CIECAM02, HSL / HSI, HSV / HSB, L $* \mathrm{u} * \mathrm{v}, \mathrm{L} * \mathrm{a} * \mathrm{~b} *$, and HCL Color space is a method used to create specifications, create, and visualize the color. In visual perception of the human eye, the color is defined by attributes such as color (hue), density (or satuation chrominance) and brightness (luminance). Computers capable of describing a color using a phosphor emission of red, green, and blue needed to adjust the color. A printing press was able to create a specific color resulting from reflexes and power absorption of the ink colors in printing paper like the colors cyan (greenish-blue), magenta (reddish purple), yellow, and black. Here are some of the commonly used color space in image processing: RGB (red, Green, Blue) Color space, CIE Color Space and HSL/I Color Space. Table 1 show the difference about State of the Art this research.

Table 1. The Difference about 2 research in Image color Extraction

\begin{tabular}{|c|c|c|c|}
\hline Research & Method & Positiveness & Lackness \\
\hline $\begin{array}{l}\text { Wang et. al. } \\
\text { 2007, Color } \\
\text { and Texture } \\
\text { Based Image } \\
\text { Segmentation } \\
\text { for Improved } \\
\text { Forest } \\
\text { Delineation [1] }\end{array}$ & $\begin{array}{l}\text { Generate } \\
\text { Algorithm }\end{array}$ & $\begin{array}{l}\text { Assuming a } \\
\text { normal } \\
\text { distribution, } \\
\text { texture color } \\
\text { combinations give } \\
\text { good results. } \\
\text { Green non-forest } \\
\text { areas can be } \\
\text { reduced by this } \\
\text { method. }\end{array}$ & $\begin{array}{l}\text { This method is } \\
\text { good only for } \\
\text { rough } \\
\text { vegetation }\end{array}$ \\
\hline $\begin{array}{l}\text { Sanz, et.al., } \\
\text { 2008, Using } \\
\text { Colour, } \\
\text { Texture and } \\
\text { Hierarchical } \\
\text { Segmentation } \\
\text { for High } \\
\text { Resolution } \\
\text { Remote } \\
\text { Sensing [2] }\end{array}$ & $\begin{array}{l}\text { Using } \\
\text { Algorithm } \\
\text { sementatio } \\
\text { n Guigues } \\
\text { scale-sets }\end{array}$ & $\begin{array}{l}\text { The combination } \\
\text { of textures and } \\
\text { colors give good } \\
\text { results. }\end{array}$ & $\begin{array}{l}\text { Changes in the } \\
\text { color channel } \\
\text { radiometric } \\
\text { and resolution } \\
\text { greatly affects } \\
\text { the } \\
\text { segmentation } \\
\text { results. }\end{array}$ \\
\hline
\end{tabular}




\section{RESULT AND DISCUSSION}

Before the color transformation stage, made the selection process as the color coordinates of the reference pixel. The selection aims to determine the color green as a reference to determine the color of the forest are included in the calculation of the forest area. Large number of pixels essentially no restriction on the number, but in this study the selection of up to five color pixels as a reference point. Election results as a color reference pixel point is presented in Figure 3 .

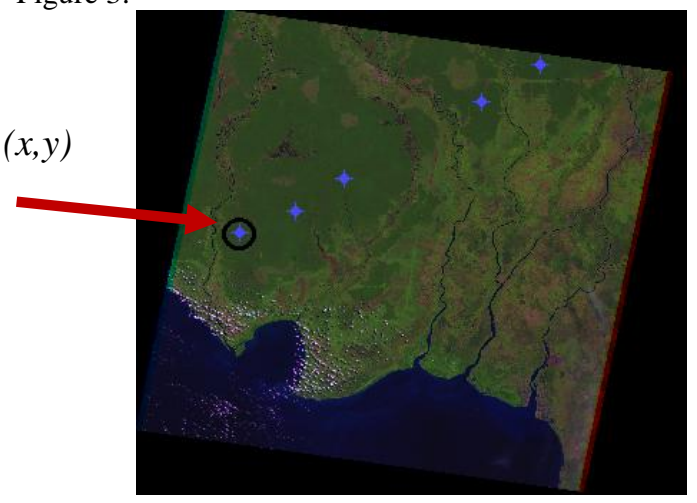

Figure 3: Pixel coordinates of the election results as a color reference

In Figure 3 appears five point pixels that have been selected, each point is selected (indicated by arrows) obtained pixel coordinates (x, y) and the value of the pixel. After the selection of the coordinates is done, the next step is to transform the overall color of the image from RGB space to the HSV color space. Figure 4 is an illustration of the results of the transformation of color in the RGB color space to HSV color space.

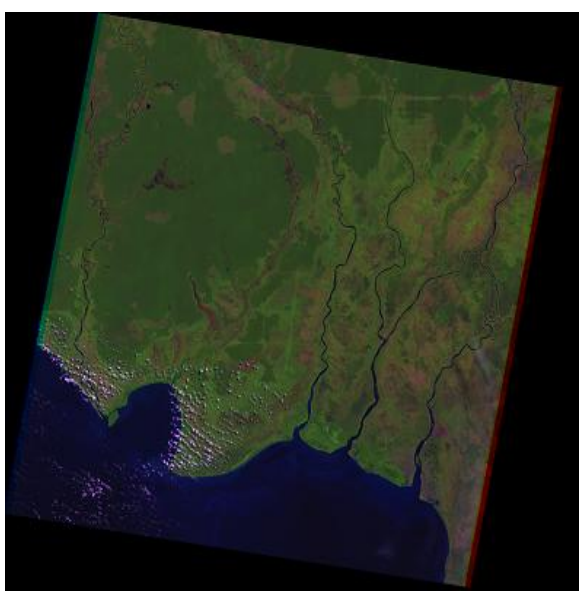

Figure 4: Original Image

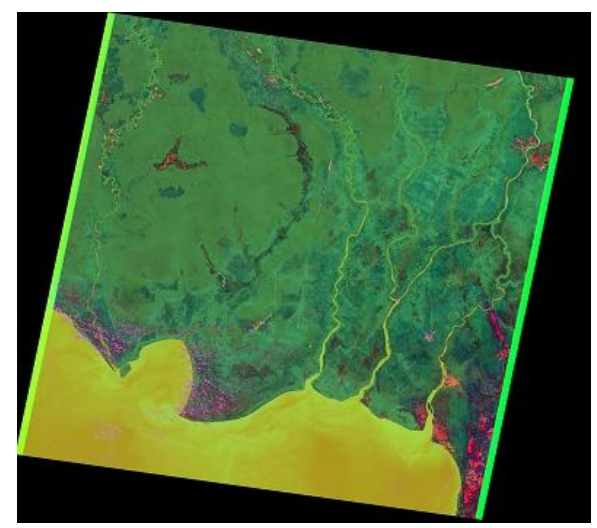

Figure 5: Image HSV

Figure 4 is a Landsat image before the color transformation, while Figure 5 is the image of the color transformation has been done. In Figure 4 shows that the color of pixels contained within can not be easily defined, in contrast with the color transformation, it becomes easy to make a selection or color separation, separation in this case is the color green to not green. Thus facilitate the process of image segmentation.

\section{CONCLUSION AND FUTURE WORK}

Suitable color space and color can represent the characteristics of forest is HSV (Hue, Saturation, Value). Each element of tolerance will result in image segmentation is different. Tolerance will determine the range of filters on the color segmentation. Parameter Hue as a determinant parameter, mindless and hue will affect the value of the selected color in the segmentation process. Also this color transformation make easily to process image segmentation other than another method that was described in Table 1 section 2 .

\section{FUTURE WORK}

For future work, it can be continued the process of extracting the color and evaluated another image characteristic such as Feature Extraction and Image Segmentation.

\section{ACKNOWLEDGMENTS}

Thanks for Gunadarma University who sponsored this research

\section{REFERENCES}

[1] Wang, Zuyuan., Ruedi, Boesch, 2007. “ Color and Texture Based Image Segmentation for Improved Forest Delneation". IEEE Transaction on Geoscience and Remote Sensing, Vol. 45 no. 10, October 2007

[2] Sanz, Roger Trias., Georges Stamon, Jean Lochet. 2008. "Using Colour, Texture and Hierarchical Segmentation for High Resolution Remote Sensing". ISPRS Journal of Photogrammetry and Remote Sensing 62 (2008) 156168 .

[3] Jolly, M.P. Dubuisson, A. Gupta. 2000, "Color and Texture Fusion: Application to Aerial Image 
Segmentation and GIS Updating", Image and Vision Computing 18 (2000), 823-832.

[4] Webster Online Dictionary, 2004, "Segment", www.merriamwebster.com

[5] Gonzalez, R.C., 2008, "Digital Image Processing (3 ${ }^{\text {rd }}$ Edition)", Nj. Pearson Education Inc. Prentice Hall.
[6] Lussiana E.T.P. 2007, “ Adaptive Edge Detction Method Based on Image Region Characteristics", Doctoral Dissertation Programme Gunadarma University.

[7] Anonimus, 2007, view as html www.irwantoshut.net/pict-rain-forest.jpg)

[8] Wang, 2001, “ Integrated Region-Based Image Retrieval”, Boston, Kluwer Academic Pulisher. 